\title{
LAVAGEM DE DINHEIRO E BITCOIN: A IDONEIDADE DA MOEDA DIGITAL COMO MEIO PARA A PRÁTICA DELITUOSA
}

\author{
MONEY LAUNDERING AND BITCOIN: THE DIGITAL CURRENCY AS A MEANS FOR THE \\ CRIMINAL PRACTICE
}

Felipe Gardelino Savino*

\begin{abstract}
Resumo:
O presente artigo tem por objetivo analisar a prática do crime de lavagem de dinheiro por meio da criptomoeda Bitcoin para, ao final, analisar possíveis medidas jurídicas para se coibir essa prática delituosa.

Palavras-chave: Lavagem de dinheiro. Criptomoedas. Bitcoin. Regulação.
\end{abstract}

\begin{abstract}
:
The purpose of this paper is to analyze the practice of the crime of money laundering through the cryptocurrency Bitcoin to, in the end, analyze possible legal measures to curb this criminal practice.
\end{abstract}

Keywords: Money laundering. Cryptocurrencies. Bitcoin. Regulation.

Introdução

William Terra de Oliveira (1998, p. 112) já escrevia, em 1998, que a dinâmica das inovações tecnológicas tem provocado mudanças nas formas tradicionais de delinquir, o que exige dos Estados respostas rápidas, principalmente no Direito Penal. Com efeito, os surgimentos de novas tecnologias cibernéticas são quase sempre razão de atenção dos Estados na medida que podem servir de instrumento para a prática de crimes.

Entre esses inventos, tem ganhado repercussão nos últimos anos a moeda digital Bitcoin, que nos chama atenção pelo fato de estar desvinculada de qualquer autoridade estatal e de seus usuários terem sua identidade mantida em sigilo, sendo assim considerada por muitos como instrumento ideal da lavagem de dinheiro.

Tendo-se em vista essas breves considerações, o presente artigo tem por objetivo analisar a idoneidade da Bitcoin como meio para a lavagem de dinheiro. Na primeira parte, discorrer-se-á sobre este crime, apontando seu conceito, origem e fases, levantando alguns desafios atuais no que diz respeito ao seu cerceamento.

A segunda parte é dedicada à moeda digital Bitcoin, explicando o seu funcionamento e as suas principais características, bem como seu surgimento dentro

\footnotetext{
* Graduando em Direito pela Faculdade de Direito Universidade de São Paulo (FDUSP). E-mail para contato: felipe.savino@gmail.com.
} 
do contexto da crise econômica de 2008. Nesse ínterim, também responderemos se as bitcoins podem ser jurídica e economicamente tidas como moedas, expondo brevemente algumas consequências jurídicas da resposta alcançada. Ao final, discorreremos sobre a instrumentalidade criminal dessa criptomoeda, abordando o caso mais paradigmático envolvendo bitcoin, lavagem e tráfico de drogas, o Silk Road.

$\mathrm{Na}$ terceira parte, analisadas a lavagem de dinheiro e a Bitcoin, trataremos sobre como a criptomoeda pode ser utilizada como meio para a prática do crime em estudo, i.e., quais são as suas características essenciais que facilitam - e também dificultam a prática de branqueamento de capitais. Também, nesta terceira parte, traçaremos um panorama sobre as regulações estrangeiras expedidas com o objetivo de se prevenir o uso da moeda digital como meio de lavagem de dinheiro, bem como trataremos sobre as medidas adotadas no Brasil com esse propósito, concluindo-se qual pode ser a medida mais eficaz e menos restritiva do que a criminalização total da criptomoeda.

1. Lavagem de dinheiro

1.1. Conceito e história da lavagem de dinheiro

O crime denominado lavagem de dinheiro consiste na prática de dar aparência de licitude aos bens obtidos por meio de um delito, colocando-os novamente no fluxo econômico legal (BADARÓ; BOTTINI, 2013, p. 21).

Não obstante essa prática nos remeter às primeiras décadas do século XX, quando grupos mafiosos nos Estados Unidos faziam uso de lavanderias para dar caráter de licitude ao dinheiro obtido pelo tráfico de bebidas alcoólicas (MAIA, 2004, p. 26), esse crime só começou a ganhar notoriedade na década de 1980, quando se percebeu o crescimento da organização de grupos criminosos, em especial daqueles envolvidos com tráfico de drogas, em decorrência do fim da Guerra Fria e do consequente aumento dos fluxos econômicos internacionais.

Inicialmente, reprimia-se o branqueamento de capitais ilícitos com figuras típicas tradicionais, como a receptação e o favorecimento. Contudo mostrou-se necessário um tipo penal específico a esta prática, dada as peculiaridades da lavagem, tais como a ocultação (BADARÓ; BOTTINI, 2013, p. 29). Nesse ínterim, os Estados começaram a se mobilizar para prevenir essa prática, e novos diplomas normativos são expedidos nesse período.

Nesse contexto, o Brasil editou a Lei n. 9.613, de 1998, que criminaliza a lavagem de dinheiro. Em sua redação original, esta previa um rol taxativo de delitos que podiam anteceder ao crime aqui tratado. Com o advento da Lei n. 12.683, de 2012, alterou-se alguns dispositivos da Lei n. 9.613, e, dentre as principais mudanças, destacase a extinção do rol de crimes antecedentes à lavagem, de forma que qualquer infração 
penal que resulte na obtenção de bens, dinheiro e valores possa configurar como o delito anterior ao branqueamento.

Dentre as previsões mais importantes dessa lei, destaca-se a criação do COAF - Conselho de Controle de Atividades Financeiras -, órgão administrativo que exerce funções regulatória, expedindo normas voltadas a setores sensíveis à lavagem de dinheiro, e repressiva (BADARÓ; BOTTINI, 2013, p. 45), instaurando processos administrativos e aplicando sanções às entidades e pessoas indicadas pela lei que descumprirem as regras e deveres de identificação de clientes e manutenção de registros e de comunicação de operações financeiras.

Diversos de seus dispositivos expressam uma preocupação em firmar cooperações entre o setor público e privado para combater a lavagem de dinheiro. As entidades listadas no art. $9^{\circ}$ são comumente denominadas de gatekeepers ("torres de vigia”), e devem observar àqueles deveres supracitados por atuarem em setores sensíveis à lavagem de dinheiro (BADARÓ; BOTTINI, 2013, p. 34-36).

\subsection{Fases da lavagem de dinheiro}

A doutrina majoritária divide a lavagem em três fases. A primeira etapa é a ocultação, ocorrendo logo após a obtenção do dinheiro sujo. Nesta etapa, não somente o dinheiro sujo que é escondido, mas também a sua natureza ilícita (CARLI, 2012, p. 187), com a intenção de lhe ser dado, ulteriormente, caráter de licitude - por exemplo, a conversão de moeda nacional em estrangeira. Por ainda manterem um contato com o dinheiro sujo, os agentes estão mais vulneráveis, de forma que é nesta etapa que se deve ter uma maior fiscalização.

Posteriormente, ocorre a dissimulação, na qual é conferido ao ativo espúrio caráter de licitude, consubstanciando a lavagem (MAIA, 2004, p. 39). Esta etapa consiste em disfarçar, maquiar o caminho percorrido pelo dinheiro sujo, realizando-se diversas operações econômico-financeiras para assim dificultar o rastreamento do dinheiro ilegal. Este é dividido em quantias menores, de forma que não é exigível o registro da operação (BARROS, 2016, p. 39), e, muitas vezes, essas operações são feitas em países distintos para dificultar o rastreamento.

A última etapa do processo de lavagem de dinheiro é a integração, na qual o capital de origem espúria é inserido no sistema econômico legal já com caráter de licitude.

Importante ressaltar que, na prática, muitas vezes é dificultoso delimitar precisamente cada uma dessas fases, sendo comum que uma fase se sobreponha à outra. Ainda assim, o processo de lavagem ainda tem por finalidade a integração do capital sujo no fluxo econômico (MAIA, 2004, p. 26). 
1.3. Desafios atuais no cerceamento à lavagem de dinheiro: a questão das criptomoedas

Com o decorrer do tempo e a intensificação da globalização, os fluxos transnacionais foram aumentando, e, junto com isso, houve um enorme progresso tecnológico-científico, fatos esses que reverberam na sociedade - inclusive no que diz respeito à criminalidade e nos meios tradicionais de delinquir.

Obviamente, as moedas digitais, definidas pela "Financial Crimes Enforcement Network" - FinCEN - como um meio de troca que opera como uma moeda em alguns ambientes, mas não têm todos os atributos de uma moeda real (i.e., a moeda de um Estado designada como moeda legal, posta em circulação e aceita como meio de troca no país de emissão), ${ }^{1}$ não seriam deixadas de lado nesse processo de inovação dos meios de delinquir.

Já há notícias de investigações de crimes nos quais os agentes faziam uso dessas moedas. No âmbito da Operação Lava Jato, durante a Operação "Pão Nosso", no qual o Ministério Público Federal investigava um desequilíbrio entre o valor de lanches fornecidos ao sistema penitenciário e o custo de produção, as autoridades desconfiavam que os investigados teriam realizados quatro operações que, juntas, totalizavam uma quantia próxima a $\mathrm{R} \$ 300.000,00$ (trezentos mil reais) fazendo uso da criptomoeda Bitcoin, criando uma nova forma de escapar da Receita Federal. ${ }^{2}$

Tal caso é um exemplo que evidencia o potencial espúrio das moedas digitais, o que leva muitos ao seguinte questionamento: teriam sido as criptomoedas criadas com a finalidade instrumental para o cometimento de delitos? Ainda há muito a discutir sobre as moedas digitais, e muitos governos ainda se mostram inseguros em relação a estas, ainda mais porque se trata de um fenômeno em relação ao qual o Direito não alcançou uma resposta definitiva sobre sua regulação. Conforme Silveira (2018, p. 109-110):

As criptomoedas ainda habitam um limbo jurídico de classificação, e, talvez por isso, criam-se expectativas e lendas sobre as possibilidades de sua utilização. Se isso é verdade hoje, era, ainda mais, nos primeiros dias de sua vida. Existem, v.g., muitas previsões mundo afora em que simplesmente se prega que as moedas virtuais criptografadas não poderiam, simplesmente, ter fins especificamente ilícitos. A pergunta, de plano, diria respeito ao que pode

\footnotetext{
1 Fonte: https://www.fincen.gov/resources/statutes-regulations/guidance/application-fincens-regulationspersons-administering. Acesso em: 29 dez. 2018. Tradução livre.

2 Fonte: https://noticias.uol.com.br/politica/ultimas-noticias/2018/03/13/lava-jato-no-rio-identifica-pela-1vez-lavagem-de-dinheiro-com-bitcoins.htm. Acesso em: 22 dez. 2018.
} 
ser destinado a fins ilícitos? Algo pode previamente ter tal destino?

Neste ínterim, a criptomoeda "Bitcoin" aparece como um instrumento hábil para a prática do delito de branqueamento de ativos ilícitos. Isto posto, passaremos ao estudo dessa moeda digital.

\section{Bitcoin}

\subsection{Conceito de Bitcoin}

Inicialmente, é necessária traçar a sútil distinção entre Bitcoin e bitcoins. A primeira é um software, uma rede de pagamentos descentralizada (i.e., sem nenhuma autoridade por trás), virtualmente pseudônima e de transferência peer-to-peer - "P2P" (as transações são feitas diretamente entre os usuários, sem o intermédio de um terceiro, como um banco) (BRYANS, 2014, p. 443), projetada no início de 2009 pelo pseudônimo Satoshi Nakamoto, quando lançou sua invenção ao mundo com o artigo "Bitcoin: A Peerto-Peer Electronic Cash System ", ${ }^{3}$ no qual, em termos técnicos, explica o funcionamento da Bitcoin.

Os pagamentos realizados nessa rede são realizados única e exclusivamente pelas criptomoedas bitcoins, cujo valor não é atribuído por governo algum, mas pelos próprios usuários da rede, sendo o "primeiro sistema de pagamentos global totalmente descentralizado" (ULRICH, 2014, p. 17). Os pagamentos realizados na rede são enviados quase instantaneamente pela Internet com taxas muito baixas. Ademais, os endereços Bitcoin, as "contas" na rede, geradas pela "carteira virtual", são gratuitos, podendo qualquer um abrir um ou mais.

\subsection{Funcionamento e características da Bitcoin}

\subsubsection{Descentralização}

A Bitcoin é desvinculada de qualquer governo, de forma que nenhum Estado pode implementar sua política monetária sobre a criptomoeda, tanto que sua oferta foi definida antecipadamente em 21 milhões de bitcoins (ZOHAR, 2015, p. 104-105). O software da Bitcoin é desenvolvido pelos próprios usuários - sendo, assim, um software aberto (open-source), de forma que qualquer indivíduo pode "verificá-lo, monitorá-lo e aprimorá-lo (este último, com o consenso de toda a comunidade)" (ULRICH, 2014, p. 82).

Disponível em: https://bitcoin.org/bitcoin.pdf. Acesso em: 3 jan. 2019. 


\subsubsection{Problema do "gasto duplo" e a mineração de bitcoin}

Uma das grandes inovações trazidas por essa moeda digital é que ela é capaz de prevenir o chamado problema do gasto duplo.

Para explicar no que consiste este problema, imaginemos a seguinte situação: ao enviar um arquivo em PDF via e-mail, o remetente não perdeu o documento, mas fez uma cópia dele, de forma que há, destarte, dois documentos idênticos. Isso pode se tornar um problema ao transportamos para as transações em moedas digitais, pois estas se tornariam simples arquivos de computador (ULRICH, 2014, p. 17), fato que, a nosso ver, poderia comprometer seu uso como moeda.

Antes do surgimento das bitcoins, sempre se contou com a ajuda de terceiros de confiança que fizessem um registro histórico das transações para garantir a validade destas - comumente, o Estado e os bancos. Para evitar o problema, estes são substituídos, na Bitcoin, pelos seus usuários, que, por meio de uma série de cálculos envolvendo algoritmos, atestam a validade das transações (LEE; LAM; 2015, p. 15-16). Esse processo é conhecido como mineração, e, aos mineradores que concluírem essa prova de trabalho (proof of work), cuja duração aproximada é de 10 minutos, são devidas novas bitcoins.

A mineração é um processo matemático. Analogicamente, o cálculo desses algoritmos se assemelha a uma contagem de números primos: os primeiros são os mais fáceis de descobrir, mas, conforme os números vão aumentando, cresce a dificuldade de se encontrar algum número que seja divisível somente por um e por ele mesmo (ULRICH, 2014, p. 19-20). Tal processo é necessário para que novas bitcoins sejam criadas até se chegar ao limite de 21 milhões de unidades.

Além da mineração, outro modo de obter bitcoins são nas exchanges, nos quais usuários podem converter bitcoins em outras moedas, tais como euro, dólar e real, ou mesmo trocá-las por bens (JEANS, 2015, p. 106).

\subsubsection{Blockchain}

Todas as transações realizadas na Bitcoin são registradas em uma espécie de "livro contábil" denominado blockchain. Para isso, a criptografia da Bitcoin se baseia em duas chaves, uma pública e uma privada (LEE; LAM, 2015, p. 21). A primeira é usada para assinar as transações na rede, e a segunda é usada para verificar assinaturas digitais em transações. A chave pública é acessível a todos os usuários da rede, e serve como endereço para se enviar as transações, e a chave privada é de exclusividade do proprietário das bitcoins.

Como o próprio nome já sugere, o blockchain é constituído por uma cadeia de blocos onde são registradas as transações na rede. "Todo novo bloco que é sucessivamente 
adicionado no blockchain se referencia ao bloco anterior, tornando exponencialmente difícil reverter transações anteriores em blocos anteriores" (LEE; LAM, 2015, p. 20). Essa é uma das grandes vantagens de se usar a Bitcoin, pois, sendo as transações realizadas nela praticamente irreversíveis, evita-se possíveis estornos (KHAN, 2015, p. 18).

Assim, uma transação típica na Bitcoin envolve cinco agentes: (i) um remetente, que inicia a transação; (ii) um receptor das bitcoins; (iii) os mineradores, que verificam as transações; (iv) a equipe central de desenvolvimento da Bitcoin, que atualiza o código da rede conforme necessário; e (v) as exchanges de Bitcoin, que facilitam a conversão de bitcoins para outras moedas e vice-versa. Essa dinâmica também ocorre no caso da lavagem de dinheiro (BRYANS, 2014, p. 447), como se verá oportunamente.

\title{
2.2.4. Pseudoanonimato
}

Por fim, um último aspecto a ser discorrido é o pseudoanonimato.

Comumente, a Bitcoin é referida como anônima, embora não seja. De fato, a Bitcoin dispensa o intermédio de um terceiro, mas não é completamente anônima a ponto de as partes não saberem nada uma da outra. A identidade de cada usuário é preservada, mas as transações são sempre registradas no blockchain, onde consta o endereço de cada usuário. Assim, é possível identificar quem está por trás das transações, especialmente se a identidade de alguém está associada a um endereço, de forma que o correto é dizer que a Bitcoin é caracterizada pelo pseudoanonimato, e não anonimato (LEE; LAM, 2015, p. 21-22). Consoante Ulrich (2014, p. 22):

\begin{abstract}
Ainda que Bitcoin seja frequentemente referido como uma moeda "anônima", em realidade, é bastante difícil permanecer anônimo na rede Bitcoin. Pseudônimos ligados a transações protocoladas no registro público podem ser identificados anos após a realização de uma troca. Uma vez que intermediários de Bitcoin estejam completamente em dia com as regulações requeridas a intermediários financeiros tradicionais, o anonimato será ainda menos garantido, porque dos intermediários de Bitcoin será exigido coletar dados pessoais de seus clientes.
\end{abstract}

\subsection{Origem histórica da Bitcoin}

\subsubsection{O movimento Cypherpunk}

Pode-se afirmar que a raiz da Bitcoin não se encontra no artigo publicado por Satoshi Nakamoto. As origens ideológicas dessa criptomoeda se encontram nas décadas de 1980 e 1990, nos Estados Unidos, com o surgimento do grupo criptoanarquista Cypherpunk. 
Esse grupo era formado por hackers libertários, que, buscando ampliar sua filosofia de liberdade e privacidade, faziam uso da deep web, espaços invisíveis na internet para assim fugir da vigilância estatal e garantir o anonimato (SILVEIRA, 2018, p. 94-95).

O movimento Cypherpunk também procurava uma moeda virtual que fosse anônima ou que pudesse ser anônima usando criptografia. Sob a influência do criptógrafo David Chaum, os membros desse movimento faziam experimentos com criptografia em busca de tal criptomoeda (LEE; LAM, 2015, p. 10).

Com o afastamento de Chaum do movimento e sua aproximação dos governos, o movimento "morreu". Todavia, o ideário Cypherpunk ressurgiu com a Crise de 2008 e o nascimento das moedas digitais. ${ }^{4}$

2.3.2. A crise de 2008, a perda da confiança da moeda e o (res)surgimento das moedas digitais

Essa crise teve seu início em 2007 com a questão das hipotecas de alto risco e a consequente "aperto da liquidez". Assim,

o setor financeiro congelou, os preços dos ativos despencaram (...) e os grandes bancos do mundo ocidental viram-se praticamente insolventes. No ano seguinte, a crise seria intensificada. Bancos e fundos de investimento buscavam desesperadamente sacar seus depósitos de instituições problemáticas. (...) Depois de seguidos resgates de bancos em dificuldades, fusões forçadas pelo Federal Reserve, acordos de "troca de liquidez" entre os principais bancos centrais do mundo ("liquidity swap"), legislações apressadas e desesperadas, o impensável ocorria: no dia 15 de setembro de 2008, um banco considerado "grande demais para quebrar" viria a falir. O Lehman Brothers entrava para a história como a maior falência dos Estados Unidos até então. A queda do Lehman foi certamente um ponto de inflexão na crise. A partir daquele momento, os bancos centrais passaram a atuar com uma discricionariedade e arbitrariedade sem precedentes no mundo desenvolvido (ULRICH, 2014, p. 38-39).

Tendo em vista a magnitude da crise e a dificuldade dos governos e dos bancos em contornar seus efeitos nefastos, começou-se a questionar a capacidade de regulação do sistema financeiro legal, colocando em xeque a legitimidade da moeda legal. Assim, abriu-se espaço para o (re)nascimento das moedas digitais, que se mostraram

Vide: BANKING on Bitcoin. Direção de Christopher Cannucciari. Estados Unidos: Gravitas Ventures, 2017. $83 \mathrm{~min}$. 
como uma alternativa àqueles que preferiam proteger o seu capital do sistema financeiro legal (WEBER, 2016, p. 29).

Assim, criou-se o terreno ideal para a criação e desenvolvimento da Bitcoin. Ao final de 2008, a primeira bitcoin foi criada, e, desde então, seu crescimento se deu de uma maneira exponencial, passando de \$ 0,00076 para hoje seu valor oscilar constantemente na casa dos milhares, servindo de objeto de especulação.

Além de objeto de especulação, as bitcoins também são utilizadas como meio de troca. A primeira compra realizada com essa criptomoeda foi realizada em maio de 2010, quando foi comprada uma pizza no valor de 10 mil bitcoins (ZOHAR, 2015, p. 104). Em países como Espanha e Estados Unidos, já há lugares onde se aceitam seu uso, seja para comprar um carro, apartamento, ou, até mesmo, fazer uma reserva em um restaurante (ZUÑIGA, 2015, p. 56).

A partir disso, começaram a surgir outras moedas digitais, tais como Ethereum, Cardano e Litecoin, cada qual com as suas peculiaridades.

\subsection{Bitcoin, uma moeda?}

Neste ponto, cuidaremos de uma espinhosa questão que gira em torno das bitcoins, qual seja, se ela pode ou não ser considerada moeda. Tendo-se em vista que o termo "moeda" apresenta diversas definições, seja no campo das ciências econômica ou jurídica, trataremos essa questão aqui sob esses dois enfoques distintos, sem a pretensão de esgotar todas as possibilidades de abordagem.

\subsubsection{Uma abordagem econômica}

Há dificuldades de se definir, dentro da teoria econômica, o conceito de moeda. Não pretendemos aqui, contudo, trabalhar o que se encontra em uma zona cinzenta, mas com aquilo que é praticamente unânime entre os economistas, i.e., as funções essenciais da moeda, quais sejam, meio de troca, unidade de conta e reserva de valor (MANKIW, 2001, p. 610).

Por meio de troca, devemos entender que a moeda "é aquilo que os compradores são aos vendedores quando desejam adquirir bens e serviços" (MANKIW, 2001, p. 611). Unidade de conta é a medida com a qual se determina o valor de determinado bem ou serviço. E, por fim, reserva de valor "é um instrumento que as pessoas usam para transferir poder aquisitivo do presente para o futuro" (MANKIW, 2001, p. 611).

Olhando para a bitcoin como meio de troca, é difícil afirmar que ela exerce tal função. Por mais que haja notícias de que compras já foram realizadas por meio dessa moeda digital, são poucas as pessoas que a detém, e menor ainda o número de pessoas que a utilizam com esse papel (YERMACK, 2015, p. 37). Yermack (2015, p. 38) ainda 
destaca que o uso de bitcoin como meio de troca exige uma espera de 10 minutos para verificar a validade da transação. Embora os comerciantes possam confiar em seus clientes para realizar uma transação mais rapidamente, isso os deixaria vulneráveis, pois há a possibilidade de os compradores gastarem as mesmas bitcoins enquanto não houver tido a confirmação da validade da transação.

Ademais, as bitcoins, em decorrência de dois principais motivos, dificilmente podem ser utilizadas como unidade de conta. Como já apontado supra, uma das características dessa moeda digital é a sua volatilidade, i.e., as variações significativas de seu preço em um intervalo curto de tempo. Tal característica dificulta o seu uso como unidade de conta, pois, os comerciantes deveriam constantemente readequar o preço de seus produtos, o que dificulta o comércio. Assim, "enquanto a volatilidade perdurar, dificilmente será adotado como unidade de conta" (ULRICH, 2014, p. 95). Ademais, o valor das bitcoins sempre está na casa dos milhares, de forma que os preços dos produtos em bitcoins quase sempre estariam nas casas decimais (ULRICH, 2014, p. 38-39).

Das três funções acima apontadas, a única que nos parece realmente exercida pela bitcoin é a terceira, i.e., reserva de valor. Esta serve para que a pessoa possa transferir seu poder aquisitivo do presente ao futuro, e não parece haver óbice algum para que as bitcoins não possam ter tal função. Isso, contudo, não é suficiente para caracterizálas como moeda, pois “a moeda não é a única reserva de valor na economia. Uma pessoa pode transferir poder aquisitivo do presente para o futuro por meio de outros ativos" (MANKIW, 2001, p. 611).

\subsubsection{Uma abordagem jurídica}

Não é pacífica dentro do Direito a definição jurídica de moeda, mas há algumas correntes dentro do Direito Monetário que tratam sobre o assunto. A partir da análise de Roberto Quiroga Mosquera (2006, p. 51-58) sobre as divergências doutrinárias quanto a esse conceito, podemos concluir que há, de modo geral, duas visões sobre o assunto.

Uma dessas correntes assume um viés positivista: é moeda aquilo que a lei diz que é moeda. "Em outros termos: a moeda corresponderá ao instrumento que os comandos normativos atribuírem função de satisfazer as prestações que apresentem um dever jurídico" (MOSQUERA, 2006, p. 56). No caso brasileiro, a moeda está definida na Lei n. 9.069, de 1995, que adota o Real como unidade do Sistema Monetário Nacional em seu art. $1^{\circ}$.

A segunda corrente, liderada por Cortez, entende que a eficácia das normas de Direito Monetário depende da confiança depositada na moeda pela sociedade, não pela autoridade legal, de forma que a moeda não deve sua existência ao Direito (DE CHIARA, 
1986, p. 56-57). Não se dispensa a necessidade de uma definição legal, mas esta não basta para tal corrente.

Sem pretendermos abordar o mérito de cada uma dessas vertentes, a nosso ver, a bitcoin não pode ser considerada moeda em nenhuma dessas duas posições: para ambas as correntes, há uma compreensão legal sobre aquilo que se depreende por moeda, variando somente a importância dada para essa atribuição. Assim, ao menos no caso da legislação pátria, bitcoin não pode ser entendida como moeda, isto porque a Lei n. 9.069/1995 considera o Real como unidade do Sistema Monetário Nacional.

\subsubsection{Algumas repercussões no Direito}

A primeira repercussão na seara jurídica, geradas pelas conclusões acima, reside na qualificação jurídica das bitcoins.

Essa moeda digital, conforme exposto acima, não é, do ponto de vista jurídico, moeda. Também não se confundem com moeda eletrônica: o próprio Banco Central, por meio do comunicado n. 25.306, de 2014, esclarece essa diferença, frisando que não cabe a aplicação da Lei n. 12.865, de 2013, às moedas digitais.

Nosso entendimento alinha-se com o posicionamento de Renato de Mello Jorge Silveira (2018, p. 116), segundo o qual as bitcoins seriam análogas a uma commodity - sendo, portanto, um bem, "coisas materiais, concretas, úteis aos homens e de expressão econômica, suscetíveis de apropriação, bem como as de existência imaterial economicamente apreciáveis" (GONÇALVES, 2015, v. 1, p. 281). Logo, as transações em bitcoins caracterizar-se-iam como permuta (ULRICH, 2014, p. 113), "contrato pela qual as partes se obrigam a dar uma coisa por outra, que não seja dinheiro" (GONÇALVES, 2015, v. 1, p. 271).

Essa afirmação pode representar repercussões em diversas áreas do Direito, tais como o Direito Privado e o Direito Tributário. Dentro da seara criminal, por se tratar de um bem, a tutela penal também recai sobre a bitcoin. Possuindo valor econômico e, logo, integrar o patrimônio de seu proprietário, a bitcoin nos parece ser protegida especialmente pelos crimes patrimoniais.

Ainda que, a nosso ver, deva ser classificada como um mero bem, nada obsta que ela seja legalmente classificada de forma diversa. A Alemanha, por exemplo, classifica as bitcoins como dinheiro privado (CAMPOS, 2015, p. 80). Assim, seu tratamento jurídico depende de como a legislação a classifica.

$\mathrm{O}$ fato de bitcoin não ser moeda também gera repercussões no cerceamento e prevenção à lavagem de dinheiro, como veremos mais adiante.

Por fim, uma última questão a ser levantada é se o uso e circulação de bitcoins caracterizaria o crime de moeda falsa, tipificada no art. 289 do Código Penal. 
A nosso ver, a resposta para tal questão é negativa. Com efeito, o objeto material do delito em questão é a "moeda metálica ou papel-moeda de curso legal no país ou no estrangeiro", de tal forma, para caracterizar o crime de moeda falsa, a bitcoin teria que se passar por uma moeda de curso legal, seja nacional - no nosso caso, o Real - ou estrangeira.

Não nos parece plausível que a bitcoin possa ser confundida com qualquer outra moeda: suas características não a permitem serem confundidas com qualquer outra moeda em curso legal. O próprio fato de ser necessário possuir uma conta na rede Bitcoin já a torna inconfundível. As bitcoins não são produtos de uma alteração ou fabricação de uma moeda de curso legal, de tal modo que não vemos como o delito do art. 289 do Código Penal poderia aqui estar caracterizado.

2.5. A instrumentalidade criminal da Bitcoin: o caso Silk Road e perspectivas de regulação

É inegável que o Direito é incapaz de acompanhar, na mesma velocidade, os eventos sociais e as inovações científicas e tecnológicas. As criptomoedas, notadamente a bitcoin, são paradigmáticas nesse sentido.

Afalta de regulação nesse campo, bem como o pseudoanonimato e a facilidade nos pagamentos oferecidos pela Bitcoin, geram muita insegurança, principalmente por parte dos Estados quanto à sua instrumentalidade criminal, principalmente no que concerne ao financiamento de atividades terroristas e lavagem de dinheiro (LEE; LAM, 2015, p. 22).

De fato, sabe-se que a bitcoin já foi utilizada para fins criminosos. $\mathrm{O}$ caso mais emblemático sobre a instrumentalidade criminal da Bitcoin é, sem dúvida alguma, o Silk Road. Esta "nada mais era do que um mercado negro visto genericamente na deep $w e b$, por onde seria possível o comércio de mercadorias ilícitas" (SILVEIRA, 2018, p. 113).

Ross Ulbricht, criador da Silk Road, projetou nesta todo aquele ideal libertário de liberdade máxima do movimento Cypherpunk, vez que prescindia de qualquer forma de regulação, e a bitcoin mostrou-se a moeda ideal para a criação de um mercado livre para as pessoas, monetizando essa parte anônima da Internet. ${ }^{5}$

Em 2013, a Receita Americana e o FBI descobriram que Ulbricht estava por trás desse mercado, sendo processado e condenado posteriormente, e as bitcoins confiscadas, por não se adequarem às leis federal e estadual, foram leiloadas.

Vide: BANKING on Bitcoin. Direção de Christopher Cannucciari. Estados Unidos: Gravitas Ventures, 2017. $83 \mathrm{~min}$ 
A partir do caso Silk Road, muitos questionamentos em torno do uso delituoso da bitcoin começaram a surgir, principalmente no que concerne à regulação das moedas virtuais. Algumas legislações foram criadas na tentativa de regulá-las, especialmente no que tange às políticas antilavagem (LEE; LAM, 2015, p. 25). A primeira legislação que busca regular as moedas digitais surgiu em Nova Iorque, em julho de 2014, a fim de garantir a segurança do consumidor, bem como prevenir crimes cibernéticos. Para tanto, o New York's Department of Financial Services fixou uma série de diretrizes a serem observadas por empresas que transacionam por bitcoins, devendo obter uma licença conhecida como "BitLicense" (SAPOVADIA, 2015, p. 263).

Ainda há muitas discussões no que concerne à regulação da Bitcoin, principalmente sobre a prevenção em relação ao crime de lavagem de dinheiro. No item 3.3.1, trataremos essa questão com maior profundidade.

\section{Bitcoin e a lavagem de dinheiro}

3.1. Vantagens e desvantagens da Bitcoin instrumento da lavagem de dinheiro

Como já fora delineado anteriormente, diversos aspectos da Bitcoin a tornam propícia para a prática de lavagem de dinheiro, dentre os quais se destacam sua rede de transações peer-to-peer, sua descentralização e o pseudoanonimato.

Quanto a essa primeira característica, o Grupo de Ação Financeira da América do Sul, em junho de 2013, emitiu um documento intitulado "Informe Sobre Nuevos Métodos de Pago: Tarjetas Prepagas, Pagos por Telefonía Móvil y Pagos por Internet", no qual destacava que o fato de as transferências na Bitcoin não requererem nenhum intermediário as tornam mais propensas e eficazes para a lavagem de dinheiro. De fato, a ausência de um intermediário para fiscalizar a origem e o destino do dinheiro é uma das vantagens que a Bitcoin oferece para a prática de lavagem de dinheiro

$\mathrm{O}$ fato de a Bitcoin não ter uma autoridade central também a torna um atrativo para os lavadores de dinheiro. Conforme Xesús Pérez López (2017, p. 155; tradução nossa):

(...) as criptomoedas são perfeitamente adaptadas às características clássicas do cibercrime: instantaneidade (velocidade das transações); distância entre o autor da infracção e o local da comissão de uma parte substancial da natureza criminal do crime; natureza transfronteiriça, com os problemas legais associados com a determinação da jurisdição competente para conhecer a infração e a cooperação internacional indispensável para buscá-la; imaterialidade e, portanto, a facilidade de eliminação de provas (a última, no entanto, reduzida em certa medida devido à natureza pública do livro de registro). 
Quanto à última característica, destacamos os apontamentos de Renato de Mello Jorge Silveira (2018, p. 114):

O ambiente da bitcoin é muito próximo ao arquétipo ideal da lavagem de dinheiro, no qual um dinheiro sujo é reinserido no mercado, sendo olvidado seu passado, uma vez que a noção de ocultação se mostra inerente ao próprio anonimato.

Não é difícil compreender a preocupação em torno dessa característica da Bitcoin: sendo ela criptografada e capaz de esconder a identidade do usuário, qualquer operação financeira por meio da Bitcoin aparentemente é possível de configurar a primeira fase da lavagem de dinheiro, qual seja, a ocultação (SILVEIRA, 2018, p. 77-78).

Ainda sobre o pseudoanonimato, destaca Silveira (2018, p. 78-79):

A questão em relação à possível situação das moedas virtuais torna-se particularmente complexa quando se verifica seu anonimato inerente. Uma das grandes políticas criminais postas contemporaneamente à legislação anti-lavagem foi, justamente, a de se restringir, senão acabar, com operações não identificadas. A transparência é parte destacada dessa política, o que se mostra - como se verá mais adiante em antítese à penumbra de difícil rastreamento virtual. Nesse sentido, uma primeira questão que se coloca seria, justamente, a da possibilidade, ou não, de se entender que a aquisição ou manutenção de valores no mundo virtual já se mostraria como lavagem de dinheiro.

De fato, o pseudoanonimato se mostra como uma característica que propicia a lavagem de dinheiro quando se olha para os participantes de uma transação na Bitcoin, listados no ponto 2.2.3. supra. Tanto o remetente quanto o receptor e o minerador tem todas as suas informações pessoais identificáveis (personally identifiable information PII) resguardadas nas transações na Bitcoin, de forma que só é possível identificá-los caso haja alguma notícia que seja possível identificar o proprietário de determinada conta na Bitcoin (BRYANS, 2014, p. 469-470) - o que, a princípio, só é possível caso algum dos participantes informe algum dado pessoal. Conforme Danilo Dias Ticami (2016, p. 257258):

Como as transações são efetuadas de forma pseudoanônima, dificilmente as metodologias tradicionais de investigação surtiriam efeito para descobrir o vendedor e comprador. $\mathrm{Na}$ realidade, uma regulamentação capaz de descobrir a identidade de ambos agentes, figura controversa e de pouca utilidade, enquanto sistemas de camuflagem do Internet Protocol (IP) e a capacidade das transações serem realizadas de qualquer lugar do planeta, tornam a persecução penal custosa para resultados insignificantes ou inexistentes. No 
tocante aos mineradores, estes igualmente são de difícil regulamentação. A identificação do minerador também se dá por pseudônimos.

Dessarte, o pseudoanonimato se mostra como a característica ideal para a lavagem de dinheiro. Na hipótese em que, por exemplo, um traficante de entorpecentes adquira 100 mil dólares com esse comércio ilegal, ele facilmente poderia realizar diversas transações por meio da Bitcoin criando contas distintas e transferindo as bitcoins entre elas, desvinculando assim o dinheiro sujo de sua origem espúria sem correr o risco de ser identificado.

Contudo, embora o pseudoanonimato possa ser uma grande vantagem aos lavadores de dinheiro, Fernando Ulrich (2014, p. 32) alerta-nos dos riscos de se usar a Bitcoin como meio para essa prática delituosa: com efeito, a rede fornece um registro público de todas as transações na blockchain, sempre ao alcance das autoridades antilavagem.

Assim, uma determinada transação suspeita de lavagem de dinheiro sempre pode ser acompanhada e fiscalizada pelas autoridades. Ainda que o usuário da rede esteja escondido por meio do pseudônimo, um pequeno descuido pode ser o suficiente para que se descubra a identidade dos envolvidos em uma transação.

Dessarte, embora a Bitcoin possa esconder a identidade de um lavador por meio do pseudoanonimato, ela também oferece riscos a este na medida em que todas as transações realizadas na rede são registradas publicamente.

Regular a equipe de desenvolvimento da Bitcoin no sentido de prevenir e combater a lavagem de dinheiro parece pouco efetivo, ainda que essa não esteja escondida sob o manto do pseudoanonimato. Por se tratar de um software aberto, a comunidade pode trabalhar no seu desenvolvimento, de forma que interromper essa equipe se torna pouco eficaz (TICAMI, 2016, p. 257-258). Dos cinco participantes listados, talvez uma possível solução se encontre nas exchanges.

\subsection{As exchanges de Bitcoin}

De todos os participantes de uma transação na Bitcoin, as exchanges aparentam ser as mais facilmente sujeitas a regulações, tendo quem entenda que a única forma de controlar o Bitcoin seria regulamentar e fiscalizar o momento da conversão entre a moeda digital e as moedas nacionalizadas (BARBOSA, 2016, p. 284).

Ademais, regular as exchanges de bitcoins também é a medida mais eficaz para se prevenir a lavagem de dinheiro: elas operam justamente no momento da ocultação, em que o lavador se encontra o mais próximo possível do dinheiro sujo, sendo assim o momento em que o agente se encontra mais vulnerável. 
Conforme Bryans (2014, p. 471), pelo fato de lidarem com moedas fiduciárias, as exchanges encaixar-se-iam, portanto, nas normas reguladoras de câmbio monetário que definem o dinheiro como moeda apoiada por um governo. Nesse sentido, muitas casas de câmbio de bitcoins já adotaram medidas para atender às exigências das autoridades no que tange à prevenção à lavagem (ULRICH, 2014, p. 32). Assim, cria-se a expectativa de que os Estados criem legislações para regular as exchanges, e assim facilitar a transparência para evitar qualquer prática criminosa (CAMPOS, 2015, p. 81).

Por não se tratar exatamente de câmbio monetário, vez que as bitcoins não são moedas, as exchanges não nos parecem estar regulamentadas pelas normas de casas de câmbio, como a Lei n. 1.807/1953: este, em um sentido genérico, é a troca de duas ou mais moedas entre si; em um sentido específico, é a troca de moeda estrangeira pela nacional (ABRÃO, 2010, p. 262). Por não se tratar de moeda, não se trata juridicamente de câmbio, sendo, portanto, inaplicáveis as normas cambiais.

Tal problema, a nosso ver, poderia facilmente ser resolvido com um ato normativo (uma resolução do Conselho Monetário Nacional, por exemplo ${ }^{6}$ ) tomando a bitcoin como moeda para fins de câmbio. Seria, assim, uma ficção jurídica para que as exchanges de bitcoin se encaixassem nas normas cambiais.

Ainda, por atuarem em um setor sensível à lavagem de dinheiro, poder-seia questionar se as exchanges de bitcoins poderiam se enquadrar no inciso I do art. $9^{\circ}$ da Lei n. 9.613/1998. ${ }^{7}$

Não nos parece acertado esse posicionamento: as bitcoins não podem ser qualificadas como moedas do ponto de vista jurídico e econômico do termo, vez que não tem as características essenciais para tal e também por estarem desvinculadas a qualquer Estado (BELLO; SAAVEDRA, 2017, p. 163), de forma que as exchanges não estariam englobadas por esse dispositivo.

Tampouco elas se encaixariam no art. $9^{\circ}$, parágrafo único, inciso IV, da referida lei. Com efeito, não há, na legislação brasileira vigente, menção expressa

\footnotetext{
6 Conforme o inciso V do art. $4^{\circ}$ da Lei n. 4.595, de 1964: “Art. $4^{\circ}$ Compete ao Conselho Monetário Nacional, segundo diretrizes estabelecidas pelo Presidente da República: V-Fixar as diretrizes e normas da política cambial, inclusive quanto a compra e venda de ouro e quaisquer operações em Direitos Especiais de Saque e em moeda estrangeira".

7 "Art. $9^{\circ}$ Sujeitam-se às obrigações referidas nos arts. 10 e 11 as pessoas físicas e jurídicas que tenham, em caráter permanente ou eventual, como atividade principal ou acessória, cumulativamente ou não: I - a captação, intermediação e aplicação de recursos financeiros de terceiros, em moeda nacional ou estrangeira;"

8 "Art. $9^{\circ}$ (...) Parágrafo único. Sujeitam-se às mesmas obrigações: IV - as administradoras ou empresas que se utilizem de cartão ou qualquer outro meio eletrônico, magnético ou equivalente, que permita a transferência de fundos;".
} 
às empresas que realizam o câmbio de moedas digitais, não nos parecendo correto uma interpretação extensiva, sob pena de gerar arbitrariedades.

Assim, entendemos que as exchanges não se encaixam em nenhuma das pessoas listadas no art. $9^{\circ}$, de forma que não estão obrigadas aos deveres listados nos arts. 10 e 11 da Lei da Lavagem de Dinheiro. O Banco Central do Brasil, por meio do Comunicado n. 31.379/2017, manifestou esse mesmo entendimento:

\begin{abstract}
As empresas que negociam ou guardam as chamadas moedas virtuais em nome dos usuários, pessoas naturais ou jurídicas, não são reguladas, autorizadas ou supervisionadas pelo Banco Central do Brasil. Não há, no arcabouço legal e regulatório relacionado com o Sistema Financeiro Nacional, dispositivo específico sobre moedas virtuais. O Banco Central do Brasil, particularmente, não regula nem supervisiona operações com moedas virtuais.
\end{abstract}

Importante salientar que, a menos que haja alguma resolução do Conselho Monetário Nacional ou afim, não se pode ter uma interpretação expansiva daqueles dispositivos por força do princípio da legalidade, um dos princípios basilares do Direito Penal.

Assim, por ora, as exchanges de bitcoins se encontram fora da sombra do Direito brasileiro. Contudo isso já está sendo tratado dentro do Congresso Nacional e pela Receita Federal, fato que será discutido no ponto 3.3.2. infra.

\title{
3.3. Perspectivas de regulação
}

\subsubsection{Regulação estrangeira}

Diversos Estados já manifestaram sua preocupação quanto à possibilidade de se usar bitcoins para a prática de lavagem de dinheiro. A tendência geral dos países, dos quais o Brasil está incluído, é emanar alguma disposição com um tratamento específico para as moedas digitais, normalmente tratando sobre as casas cambiais e as transações realizadas pelas empresas, mas sem trazer uma mudança significativa nas leis antilavagem.

No continente europeu, a European Banking Authority (EBA), órgão responsável por monitorar as atividades econômicas vigentes e aquelas que se encontram em ascensão, emitiu um parecer em 2012 alertando quanto aos riscos e benefícios das moedas digitais, bem como aconselhando às instituições financeiras a não realizar qualquer transação com essas e solicitando à União Europeia que criasse normas específicas para a prevenção de lavagem de dinheiro (BARBOSA, 2016, p. 277).

No âmbito da União Europeia, o Parlamento Europeu apoiou uma proposta da União Europeia de reformar a Diretiva n. 2015/849, que trata sobre a prevenção da lavagem de dinheiro e sobre o uso do sistema financeiro para a prática desse crime, para 
incluir as plataformas de intercâmbio de moeda digital, sugerindo também à Comissão a revisar as diretivas relativas a contas e serviços de pagamento e a dinheiro eletrônico (PÉREZ LÓPEZ, 2017, p. 150-151).

Alguns Estados, na ausência de regulação específica, têm aplicado a legislação já existente. A França, por exemplo, estabeleceu que a conversão das bitcoins em euro fosse de responsabilidade dos bancos, devendo estes verificar se há observância dos padrões estipulados pela Agência de Antilavagem de dinheiro francesa (BARBOSA, 2016, p. 300).

Há também Estados que optam por vedar qualquer transação por meio de moeda digital. É o caso, por exemplo, de Bangladesh, Bolívia (BARBOSA, 2016, p. 297), China, Índia e Tailândia (CHOO, 2015, p. 301).

O Canadá criou uma regulação para as moedas digitais com a finalidade de prevenir a lavagem e o terrorismo: aprovou-se uma lei estabelecendo as diretrizes a serem aplicadas aos negócios que utilizarem as moedas digitais, abarcando também as entidades estrangeiras que ofertam esses serviços (SAPOVADIA, 2015, p. 299), ordenando que as empresas declarassem as vendas efetuadas por meio das bitcoins e os lucros com a especulação da moeda (CAMPOS, 2015, p. 79). Ademais, em junho de 2018, anunciouse que seriam implementadas novas regulamentações para as bolsas de criptomoedas e processadores de pagamento. ${ }^{9}$

Nos Estados Unidos, há a possibilidade de uma pluralidade no tratamento jurídico-penal: não obstante sejam aplicadas, no âmbito federal, as regulações antilavagem, notadamente o Money Laundering Control Act, dentro dos limites regulatórios possíveis, tanto no tocante à prevenção quanto à punição (BRYANS, 2014, p. 455-456), os estados também podem legislar e criar regulações concernentes às moedas digitais, das quais já destacamos o plano "BitLicense", já mencionado no item 2.5. supra.

3.3.2. Regulação na legislação brasileira: os Projetos de Lei ns. 2.303/2015, 2.060/2019 e 3.825/2019 e a Instrução Normativa n. 1.888/2019

Por ora, não há nenhuma legislação em vigor que regule as moedas digitais no Brasil no sentido de prevenir a lavagem de dinheiro, embora haja algumas tentativas.

A primeira dessas tentativas foi realizada em 2015, quando foi apresentado ao Congresso Nacional o Projeto de Lei n. 2.303/2015, arquivado atualmente.

Tomando por base um relatório especial do Banco Central Europeu (BCE) de outubro de 2012, atualizado em fevereiro de 2015, o Projeto dispõe "sobre a inclusão das moedas virtuais e programas de milhagem aéreas na definição de 'arranjos

Fonte: https://www.bitcoinregulation.world/Canada. Acesso em: 28 maio 2019. 
de pagamento' sob a supervisão do Banco Central". Justificou-se que, não obstante as operações realizadas pudessem estar sob a supervisão do COAF, a transparência legislativa seria necessária para evitar qualquer questionamento judicial.

Chama-nos a atenção que o referido Projeto busca, em seu art. $2^{\circ}$, acrescentar um parágrafo $4^{\circ}$ ao art. 11 da Lei n. 9.613/1998, tratando expressamente sobre as moedas digitais. In verbis:

Art. $2^{\circ}$ Acrescente-se o seguinte $\S 4^{\circ}$ ao art. 11 da Lei 9.613, de 3 de março de 1998:

Art. $11-\S 4^{\circ}$ As operações mencionadas no inciso I incluem aquelas que envolvem moedas virtuais e programas de milhagens aéreas.

Parece-nos acertada essa disposição no que tange ao cerceamento à lavagem de dinheiro, embora insuficiente. Tal medida deixa claro que todas as pessoas listadas no art. $9^{\circ}$ devem também cumprir com os deveres dos artigos subsequentes em se tratando de operações com moedas digitais.

Contudo tal disposição não é clara quanto às exchanges. Como já argumentado anteriormente, elas não se encaixam em nenhuma das pessoas listadas atualmente na lei antilavagem, e essa mudança legislativa ainda não é suficiente para que elas sejam enquadradas no rol do art. $9^{\circ}$ da Lei n. 9.613/1998, pois as bitcoins ainda não seriam moedas à luz do Direito brasileiro.

A segunda tentativa se deu em abril de 2019, quando se apresentou ao Congresso uma nova proposta de regime jurídico dos criptoativos - o Projeto de Lei n. $2.060 / 2019$.

Tal Projeto, contudo, não faz menção expressa à lavagem de dinheiro, tampouco à Lei n. 9.613/1998, mas apenas cria um tipo penal:

Art. $6^{\circ}$ O Decreto-Lei n. 2.848, de 7 de dezembro de 1940 (Código Penal), passa a vigorar acrescido do seguinte artigo 292-A:

Art. 292-A. Organizar, gerir, ofertar carteiras, intermediar operações de compra e venda de Criptoativos com o objetivo de pirâmide financeira, evasão de divisas, sonegação fiscal, realização de operações fraudulentas ou prática de outros crimes contra o Sistema Financeiro, independentemente da obtenção de benefício econômico:

Pena - detenção, de um a seis meses, ou multa.

No nosso entendimento, esse tipo pode gerar divergências: não se menciona expressamente à lavagem de dinheiro, apenas se remete aos "outros crimes contra o Sistema Financeiro". Assim, a lavagem de dinheiro estaria incluída nessa expressão? É 
razoável entender que não, vez que os crimes contra o sistema financeiro têm uma lei própria - a Lei n. 7.492, de 1986.

De qualquer forma, esse Projeto pouco ou nada contribui para a prevenção da lavagem de dinheiro, pois nenhum de seus dispositivos preveem normas reguladoras das transações em bitcoins, tampouco das exchanges.

Em julho de 2019, foi apresentado o Projeto de Lei n. 3.825, visando a disciplinar os serviços referentes a operações realizadas com criptoativos em plataformas eletrônicas de negociação. Este último Projeto se destaca dos demais por claramente focar nas exchanges de criptomoedas, e a necessidade de regulá-las foi ressaltada na justificação da proposta. No que tange à prevenção à lavagem de dinheiro, escreveu-se "que o setor de criptoativos submeter-se-á às medidas de prevenção e combate à lavagem de dinheiro e outras práticas ilícitas previstas na Lei n. 9.613, de 1998 (Lei de Lavagem de Dinheiro)".

Propõe neste projeto que as atividades das exchanges devam ser aprovadas e reguladas pelo Banco Central do Brasil, ao qual também serão incumbidas diversas competências concernentes às transações e exchanges de criptoativos, podendo a autarquia federal exigir diversas informações das casas cambiais de criptomoedas.

Um último aspecto a destacar desse Projeto de Lei é que ele expressamente prevê a inclusão das exchanges de criptomoedas no rol de pessoas e entidades sujeitas aos mecanismos de controle previstos nos arts. 10 e 11 da Lei n. 9.613/1998. In verbis:

Art. 15. O parágrafo único do art. $9^{\circ}$ da Lei n. 9.613, de 3 de março de 1998, passa a vigorar com a seguinte redação:

Art. $9^{\circ}$ - Parágrafo Único.

XIX - as empresas que prestam serviços referentes a operações realizadas com criptoativos em plataforma eletrônica, inclusive intermediação, negociação ou custódia. (NR).

Por fim, a única regulação que está efetivamente em vigor no Brasil é a Instrução Normativa n. 1.888, da Receita Federal, que entrou em vigor em $1^{\circ}$ de agosto de 2019. Tal Instrução institui obrigações de prestação de informações concernentes às operações realizadas com criptoativos à Secretaria Especial da Receita Federal. Tal Instrução vai ao encontro do que defendermos anteriormente ao estabelecer, em seu art. $6^{\circ}$, que as exchanges estão obrigadas a prestar informações. Dentre os deveres criados no art. $7^{\circ}$, destaca-se o dever de informar a data da operação, os titulares da operação, o criptoativo usado e a quantidade negociada (incido I, alíneas $a, c, d$ e $e$ ), o que consegue contornar eficazmente o problema do pseudoanonimato na prática da lavagem de dinheiro. 
Conclusões

Com o nascimento da Bitcoin, surgiu aos lavadores de dinheiro mais uma via para delinquir. Em um primeiro momento, essa moeda digital aparece como meio ideal para a prática de lavagem de dinheiro, vez que as transações dispensam um intermediário e que a identidade de seus usuários se mantém escondida sob o manto do pseudoanonimato.

$\mathrm{O}$ fato de todas as transações realizadas na rede Bitcoin serem registradas no blockchain, sendo acessíveis ao público, é uma grande desvantagem àquelas que desejam desvincular o dinheiro sujo de sua origem espúria, de forma que esse aspecto torna a moeda digital menos atrativa aos lavadores de dinheiro.

Dentre todos os entes que participam de uma transação na Bitcoin, as exchanges de bitcoins são os únicos que podem ser efetivamente regulados, devendo, portanto, exercer o papel de gatekeepers, cooperando com as autoridades antilavagem nas operações consideradas suspeitas ou anormais. Nesse sentido, o Projeto de Lei $\mathrm{n}$. 3.825/2019 e a Instrução Normativa n. 1.888/2019 visam a regular as exchanges de criptoativos, submetendo-as aos mecanismos de controle de lavagem de dinheiro bem como ao Banco Central do Brasil.

Tais medidas se apresentam como meios eficazes ao combate à lavagem de dinheiro e menos restritiva ao uso da moeda digital, pois a criminalização do seu uso é providência pouco ou nada eficaz, vez que quase todos os participantes das transações têm a identidade escondida pelo pseudoanonimato e contam com outros meios de adquirir bitcoins para além das exchanges.

São Paulo, fevereiro de 2020.

\section{Referências}

ABRÃO, Nelson. Direito bancário. 13. ed. atualizada pelo Juiz Carlos Henrique Abrão. São Paulo: Saraiva, 2010.

AMBOS, Kai. Lavagem de dinheiro e direito penal. Porto Alegre: safE, 2017.

BADARÓ, Gustavo Henrique Righi Ivahy; BOTTINI, Pierpaolo Cruz. Lavagem de dinheiro: aspectos penais e processuais penais: comentários à Lei 9.613/1998, com as alterações da Lei 12.683/2012. 2. ed. rev., atual. e ampl. São Paulo: Revista dos Tribunais, 2013.

BARBOSA, Tatiana Casseb Bahr de Miranda. Regulamentação internacional de moedas digitais. In: BARBOSA, Tatiana Casseb Bahr de Miranda. (coord.). A revolução das moedas digitais: bitcoins e altcoins: aspectos jurídicos, sociológicos, econômicos e da ciência da computação. Cotia, SP: Editora Revoar, 2016. p. 260-317. 
BARROS, Marco Antonio de. Lavagem de capitais: crimes, investigação, procedimento penal e medidas preventivas. 4. ed. Curitiba: Juruá, 2016.

BELLO, Douglas Sena; SAAVEDRA, Giovani Agostini. Breves notas sobre compliance e prevenção à lavagem de dinheiro em bitcoins exchanges. DELICTAE: Revista de Estudos Interdisciplinares sobre o Delito, Belo Horizonte, v. 2, n. 3, p. 159-169, dez. 2017.

BRASIL. Lei n. 9.613, de 3 de março de 1998. Dispõe sobre os crimes de "lavagem" ou ocultação de bens, direitos e valores; a prevenção da utilização do sistema financeiro para os ilícitos previstos nesta Lei; cria o Conselho de Controle de Atividades Financeiras - COAF, e dá outras providências. Portal do Planalto, Brasília, DF, mar. 1998. Disponível em: http://www.planalto.gov.br/ccivil_03/ leis/19613.htm.

BRYANS, Danton. Bitcoin and money laundering: mining for an effective solution. Indiana Law Journal, Bloomington, v. 89, n. 1, p. 441-472, 2014.

CAMPOS, Gabriela Isa Rosendo Vieira. Bitcoin: consequências jurídicas do desenvolvimento da moeda virtual. Revista Brasileira de Direito, Passo Fundo, v. 11, n. 2, p. 77-84, 2015.

CARLI, Carla Veríssimo de. Lavagem de dinheiro: ideologia da criminalização e análise do discurso. 2. ed. Porto Alegre: Verbo Jurídico, 2012.

CHOO, Kim-Kwang Raymond. Cryptocurrency and virtual currency: corruption and money laundering/terrorism financing risks? In: LEE, David Kuo Chuen (ed.). Handbook of digital currency: bitcoin, innovation, financial instruments, and big data. London: Elsevier, 2015. p. 283308.

DE CHIARA, José Tadeu. Moeda e ordem jurídica. 1986. Tese (Doutoramento em Direito) Faculdade de Direito, Universidade de São Paulo, São Paulo, 1986.

GONÇALVES, Carlos Roberto. Direito civil brasileiro. 12. ed. São Paulo: Saraiva, 2015. v. 3: contratos e atos unilaterais.

GONÇALVES, Carlos Roberto. Direito civil brasileiro. 13. ed. São Paulo: Saraiva, 2015. v. 1: parte geral.

JEANS, Ethan D. Funny money or the fall of fiat: bitcoin and forward-facing virtual currency regulation. Colorado Technology Law Journal, Boulder, v. 13, n .1, p. 99-128, 2015.

KHAN, Akif. Bitcoin - payment method or fraud prevention tool? Computer Fraud \& Security, [s. l.], v. 2015, n. 5, p. 16-19, May 2015.

LEE, David Kuo Chuen; LAM, Pak Nian. A light touch of regulation for virtual currencies. In: LEE, David Kuo Chuen (ed.). Handbook of digital currency: bitcoin, innovation, financial instruments, and big data. London: Elsevier, 2015. p. 309-326. 
LEE, David Kuo Chuen; LAM, Pak Nian. Introduction to bitcoin. In: LEE, David Kuo Chuen (ed.). Handbook of digital currency: bitcoin, innovation, financial instruments, and big data. London: Elsevier, 2015. p. 5-31.

LEMOS, Marcela. Lava Jato no Rio identifica pela $1^{\text {a }}$ vez lavagem de dinheiro com bitcoins. UOL, São Paulo, 13 mar. 2018. Política. Disponível em: https:/noticias.uol.com.br/politica/ultimasnoticias/2018/03/13/lava-jato-no-rio-identifica-pela-1-vez-lavagem-de-dinheiro-com-bitcoins.htm. Acesso em: 22 dez. 2018.

MAIA, Rodolfo Tigre. Lavagem de dinheiro (lavagem de ativos provenientes de crime): anotações às disposições criminais da Lei n. 9.613/98. 1. ed., 2. tiragem. São Paulo: Malheiros, 2004.

MANKIW, N. Gregory. Introdução à economia: princípios de micro e macroeconomia: texto básico nas melhores universidades. 2. ed. Rio de Janeiro: Elsevier, 2001.

MOSQUERA, Roberto Quiroga. Direito monetário e tributação da moeda. São Paulo: Dialética, 2006.

OLIVEIRA, William Terra de. A criminalização da lavagem de dinheiro: aspectos penais da Lei

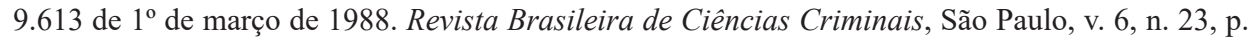
111-129, jul./set. 1998.

PÉREZ LÓPEZ, Xesús. Las criptomonedas: consideraciones generales y empleo de las criptomonedas como instrumento de blanqueo de capitales en la Unión Europea y en España. Revista de Derecho Penal y Criminologia, Madrid, n. 18, p. 141-187, jul. 2017.

SAPOVADIA, Vrajlal. Legal issues in cryptocurrency. In: LEE, David Kuo Chuen (ed.). Handbook of digital currency: bitcoin, innovation, financial instruments, and big data. London: Elsevier, 2015. p. 253-266.

SILVEIRA, Renato de Mello Jorge. Bitcoin e suas fronteiras penais: em busca do marco penal das criptomoedas. Belo Horizonte: Editora D’Plácido, 2018.

TICAMI, Danilo Dias. Considerações acerca do anonimato nas transações de moedas criptografadas e sua utilização como subterfúgio para facilitação na lavagem de dinheiro. In: BARBOSA, Tatiana Casseb Bahr de Miranda. (coord.). A revolução das moedas digitais: bitcoins e altcoins: aspectos jurídicos, sociológicos, econômicos e da ciência da computação. Cotia, SP: Editora Revoar, 2016. p. $235-260$.

ULRICH, Fernando. Bitcoin: a moeda na era digital. São Paulo: LVM, 2014.

WEBER, Beat. Bitcoin and the legitimacy crisis of money. Cambridge Journal of Economics, Oxford, v. 40, n. 1, p. 17-41, Jan. 2016.

YERMACK, David. Is bitcoin a real currency? An economic appraisal. In: LEE, David Kuo Chuen (ed.). Handbook of digital currency: bitcoin, innovation, financial instruments, and big data. London: Elsevier, 2015. p. 31-44. 
ZOHAR, Aviv. Bitcoin: under the hood. Communications of the ACM, New York, v. 58, n. 9, p. 104-113, Sept. 2015.

ZÚÑIGA, Ángeles. 'Bitcoin': mucho más que una moneda. Escritura Pública, Madrid, n. 92, p. 56-57, 2015.

\section{Referências na internet}

CANADA. Bitcoin regulation. [S. l.], [201-]. Disponível em: https://www.bitcoinregulation.world/ Canada.

NAKAMOTO, Satoshi. Bitcoin: a peer-to-peer electronic cash system. [S. l.], [2008]. Disponível em: https://bitcoin.org/bitcoin.pdf.

UNITED STATES OF AMERICA. Department of the Treasury. Financial Crimes Enforcement Network. Application of FinCEN's regulations to persons administering, exchanging, or using virtual currencies. Mar. 2013. Disponível em: https://www.fincen.gov/resources/statutesregulations/guidance/application-fincens-regulations-persons-administering.

\section{Filmografia}

BANKING on Bitcoin. Direção: Christopher Cannucciari. El Segundo, CA: Gravitas Ventures, 2016. (83 $\mathrm{min})$. 